\title{
Introduction to Dr. Choi's Feature Section
}

\author{
Morton A. Meyers \\ Department of Radiology, School of Medicine, Health Sciences Center, State University of New York, Stony Brook, New York, \\ NY 11794-8460, USA
}

Byung Ihn Choi, M.D., Ph.D. is a world renowned radiologist with widely ranging achievements in abdominal imaging, and a particular expertise in hepatobiliary disease (Fig. 1).

To selectively list only some of his accomplishments and contributions is to indicate his productivity in clinical and scientific research, teaching, and administration not only domestically but internationally as well, in ceaselessly advancing the goals of imaging.

Dr. Choi is president of the Asian Oceanian Society of Radiology (AOSR), the Korean Association for the Study of the Liver (KASL), president-elect of the Asian Society of Abdominal Radiology (ASAR), and immediate past president of the Asian Federation of Societies of Ultrasound in Medicine and Biology (AFSUMB). Past chair of the Department of Radiology at the Seoul National University, he is also a former president of the Korean Society of Radiology (KSR), Korean Society of Ultrasound in Medicine (KSUM) and Korean Society of Abdominal Radiology (KSAR) and first vice president of the World Federation of Ultrasound in Medicine and Biology (WFUMB) and a member of the executive committee of the International Society of Radiology (ISR). In 2007, the RSNA awarded him honorary membership, a distinction he has been given by ten other international and regional societies. He has authored more than 300 scientific papers and 28 textbook chapters and presented more than 250 lectures internationally.

I first personally met Professor Choi in 1986 in Seoul and he has served as a long-standing distinguished member of Abdominal Imaging's editorial board, so it is a particular pleasure and honor to introduce him to the

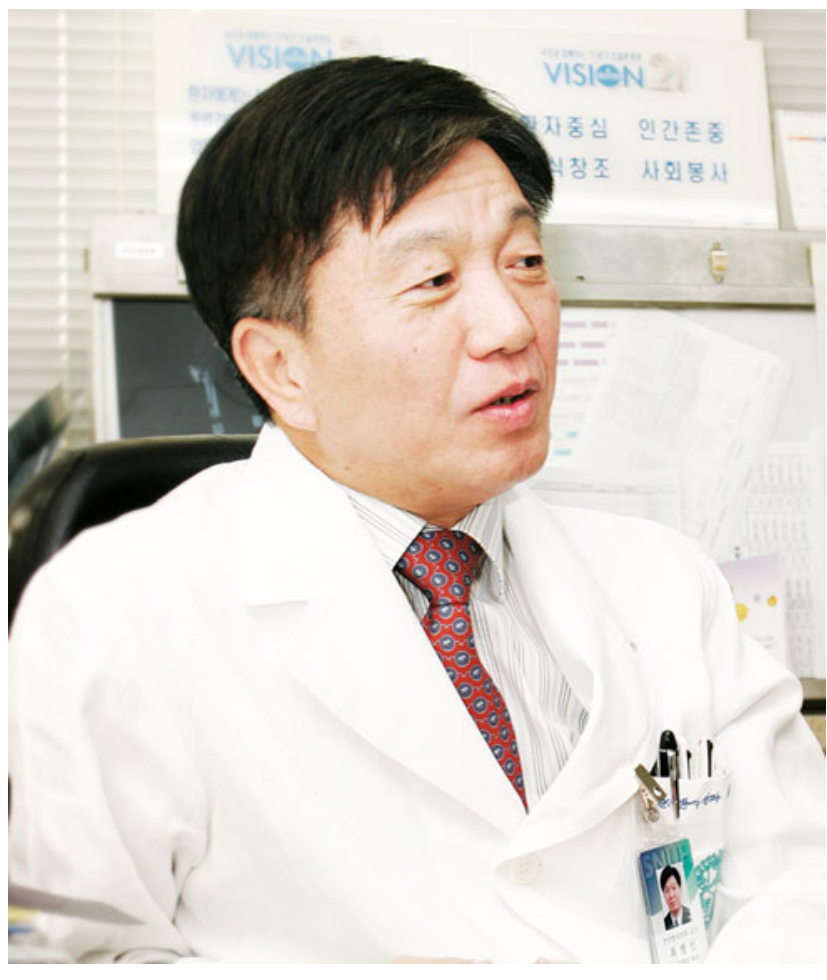

Fig. 1. Byung Ihn Choi, M.D., Ph.D.

journal's readership as Guest Editor of this issue's Feature Section. He has compiled an outstanding presentation of precision and insight that serves as today's paradigm. 